\title{
Kinship analysis of the Jomon skeletons unearthed from a double burial at the Usu-Moshiri site, Hokkaido, Japan
}

\author{
NOBORU ADACHI ${ }^{1 *}$, TOSHIHIKO SUZUKI ${ }^{2}$, KAZUHIRO SAKAUE $^{1}$, \\ WATARU TAKIGAWA ${ }^{1}$, NAOYUKI OHSHIMA ${ }^{3}$, YUKIO DODO $^{1}$ \\ ${ }^{1}$ Department of Anatomy and Anthropology, Tohoku University School of Medicine, 2-1 Seiryo-machi, Aoba-ku, Sendai, 980-8575 Japan \\ ${ }^{2}$ Division of Dental and Craniofacial Anatomy, Tohoku University School of Dentistry, Sendai, Japan \\ ${ }^{3}$ Board of Education Date City, Date, Hokkaido, Japan
}

Received 28 December 2004; accepted 24 May 2005

\begin{abstract}
Kinship analysis was performed on a Jomon double burial from the Usu-Moshiri site in Hokkaido, Japan, using odontometric data in conjunction with mitochondrial DNA data. Q-mode correlations with respect to tooth crown measurements indicated a low similarity between the two adult female skeletons found from this burial. Moreover, mitochondrial DNA analysis revealed that these individuals were not maternal relatives. Consequently, judging from both morphological and genetic evidence, these skeletons are more likely to have been unrelated rather than consanguineous. This is the first report that provides anthropological evidence for a lack of kinship of skeletons discovered from a Jomon double burial.
\end{abstract}

Key words: odontological kinship analysis, ancient DNA, double burial, Jomon

\section{Introduction}

The relationship between individuals from a double burial is important for reconstructing prehistoric funerary behavior because of the possibility that such individuals were consanguineous or had a strong social relationship. Heretofore, kinship analyses of ancient skeletons have been performed based on morphological studies (e.g. Spence, 1974; Sjøvold, 1975; Doi et al., 1985, 1986; Alt et al., 1997). Above all, tooth size proportions were statistically confirmed to reflect the hereditary background of both parents through studies based on consanguineous modern Japanese (Doi et al., 1986), and similarity analysis using tooth size proportions has been applied to specific cases to infer kinship of prehistoric Jomon and protohistoric Kofun people (Hanihara et al., 1983; Doi et al., 1986; Tanaka, 1995; Matsumura and Nishimoto, 1996).

Although morphological methods are useful, they cannot provide decisive information about kinship. DNA analysis, an established method in forensic kinship determination, has been applied successfully to ancient skeletal specimens (e.g. Kurosaki et al., 1993; Oota et al., 1995; Delefosse and Hänni, 1997; Shinoda and Kanai, 1999). However, most ancient DNA studies are limited to mitochondrial DNA (mtDNA), because its survival in ancient skeletons is more likely than nuclear DNA due to its high copy numbers in a cell. Therefore, on most ancient skeletons, only maternal kinship can be estimated by DNA analysis.

To overcome this disadvantage, similarity analysis of

* Corresponding author. e-mail: nadachi@mail.tains.tohoku.ac.jp phone: +81-22-717-8026; fax: +81-22-717-8030

Published online 13 September 2005

in J-STAGE (www.jstage.jst.go.jp) DOI: 10.1537/ase.041228 tooth size proportions, which reflects the genetic effect of the paternal line as well as the maternal line, was combined with mtDNA analysis in recent studies, and this combination analysis was confirmed to be useful to infer the relationship between individuals unearthed from archaeological sites (Shinoda et al., 1998; Corruccini et al., 2002; Adachi et al., 2003).

In the present study, we examined the relationship between two adult female skeletons excavated from the double burial at the Usu-Moshiri site, Hokkaido, Japan.

\section{Materials and Methods}

\section{Skeletal materials}

The Usu-Moshiri site is located on a small island in Usu Bay in Date City, southwestern Hokkaido, Japan (Figure 1). Excavations at the site were carried out from 1985 to 1989 under the direction of one of the authors (Y.D.). Twenty-one pit graves of the Final Jomon to Epi-Jomon periods were found, and the skeletal remains of more than 50 individuals associated with many grave goods were unearthed (Ohshima et al., 1989, 1990).

Two double burials were found at the site: two juvenile individuals excavated in 1985, and two adults unearthed in 1988. The adult skeletons were well preserved, and were named 16A and 16B, respectively. These skeletons were discovered in a grave located between rocks covered with soil. The skeletons were buried in the fetal position, with the head of specimen $16 \mathrm{~A}$ pointing west, and that of specimen $16 \mathrm{~B}$ pointing east. Of the two double burials found from the UsuMoshiri site, the juvenile skeletons were buried in a squatting position and their head directions were unclear. Therefore, the apparently opposing head directions were observed only in specimens $16 \mathrm{~A}$ and 16B. Both skeletons wore shell 


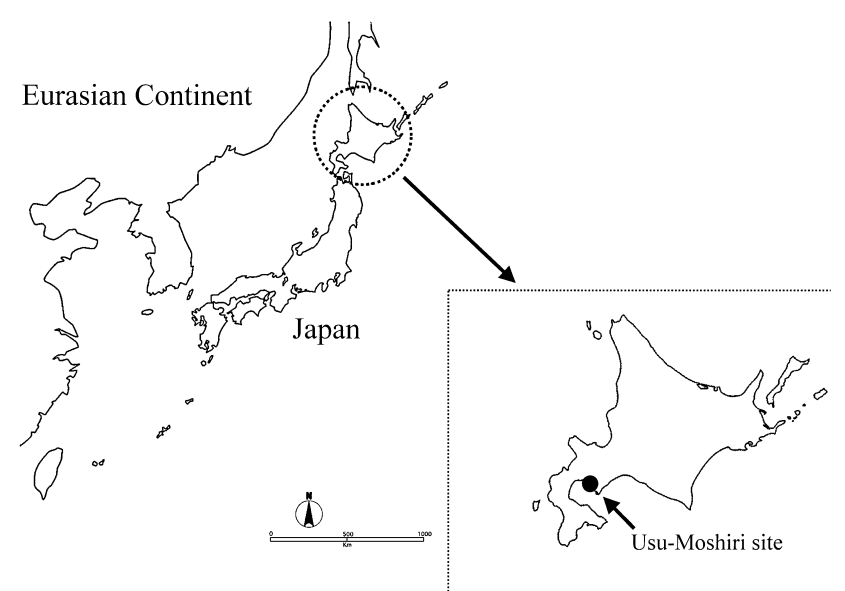

Figure 1. Map of the Usu-Moshiri site, located in the southwestern area of Hokkaido, Japan.

bracelets, which might be Oh-tsutanoha (Patella optima) and Benkei-gai (Glycymeris albolineata), on their left forearms (Figure 2). Based on morphological evidence (Table 1), the age of these specimens was estimated at late thirties to early forties for 16A and late twenties to early thirties for
16B. Both specimens were sexed as female. As these two skeletons were situated side by side and maintained anatomical articulations, they were considered to have been buried at the same time. Judging from the latest style of Jomon pottery (Ohora A) found from the grave, the date of burial was estimated at about 2500 years ago, corresponding to the Final Jomon era in Hokkaido (Ohshima et al., 1989).

The preservation state of the skulls and permanent teeth in specimens 16A and 16B is shown in Figure 3 and Figure 4.

\section{Similarity of tooth size proportion \\ Measurement}

Mesiodistal and buccolingual diameters of the permanent tooth crowns of each skeleton were measured to the nearest $0.01 \mathrm{~mm}$ with a digital sliding caliper (Mitutoyo NTD 1010C) according to the method of Fujita (1949). The teeth examined and their sizes are listed in Table 2. In specimen $16 \mathrm{~B}$, antemortem extraction of the upper right second incisor was observed and the upper left second incisor was lost after reconstructing the skull. Therefore the upper second incisor was not used to estimate the similarity of tooth size proportions.

Each tooth was measured twice and the average was recorded. The average of both sides was used as the representative value of that tooth. However, the mesiodistal diam-

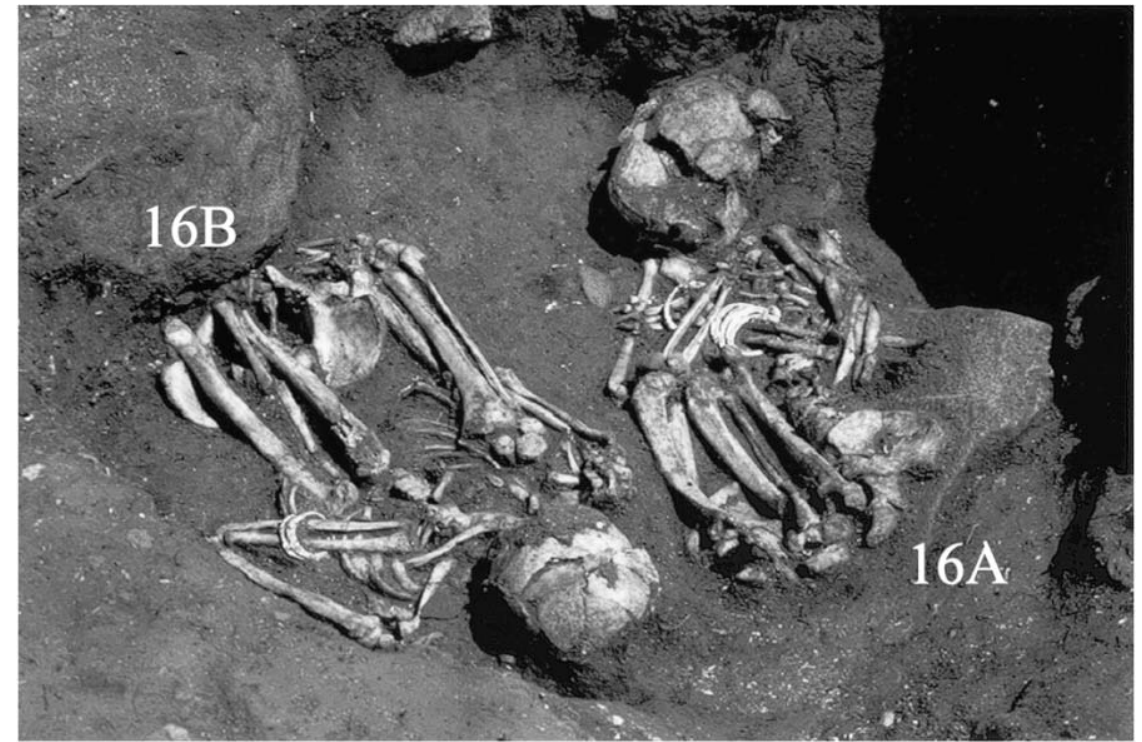

Figure 2. The burial of skeletal specimens $16 \mathrm{~A}$ and $16 \mathrm{~B}$.

Table 1. Morphological features of the skeletons used to estimate age and sex

\begin{tabular}{|c|c|c|}
\hline & $16 \mathrm{~A}$ & 16B \\
\hline Upper and lower M3 & Fully erupted & Fully erupted \\
\hline Pubic symphysis & $\begin{array}{l}\text { The formation of all but the ventral margin is com- } \\
\text { plete. Bone absorption is not observed on the sym- } \\
\text { physial surface. }\end{array}$ & $\begin{array}{l}\text { Only the formation of the dorsal margin is com- } \\
\text { plete. The horizontal ridges and furrows remain on } \\
\text { the symphysial surface. }\end{array}$ \\
\hline Sternal end of clavicle & Completely fused & Partly fused \\
\hline Greater sciatic notch & Wide & Wide \\
\hline Subpubic angle & Unable to examine & Wide \\
\hline
\end{tabular}




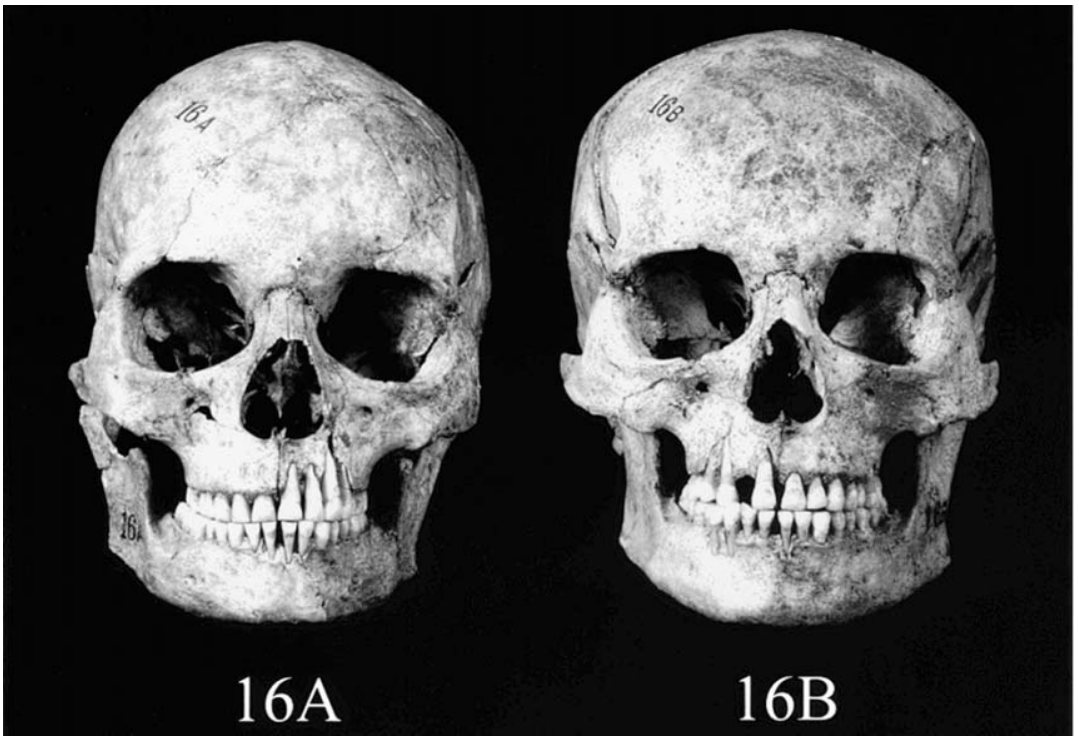

Figure 3. Skulls of skeletal specimens 16A and 16B.

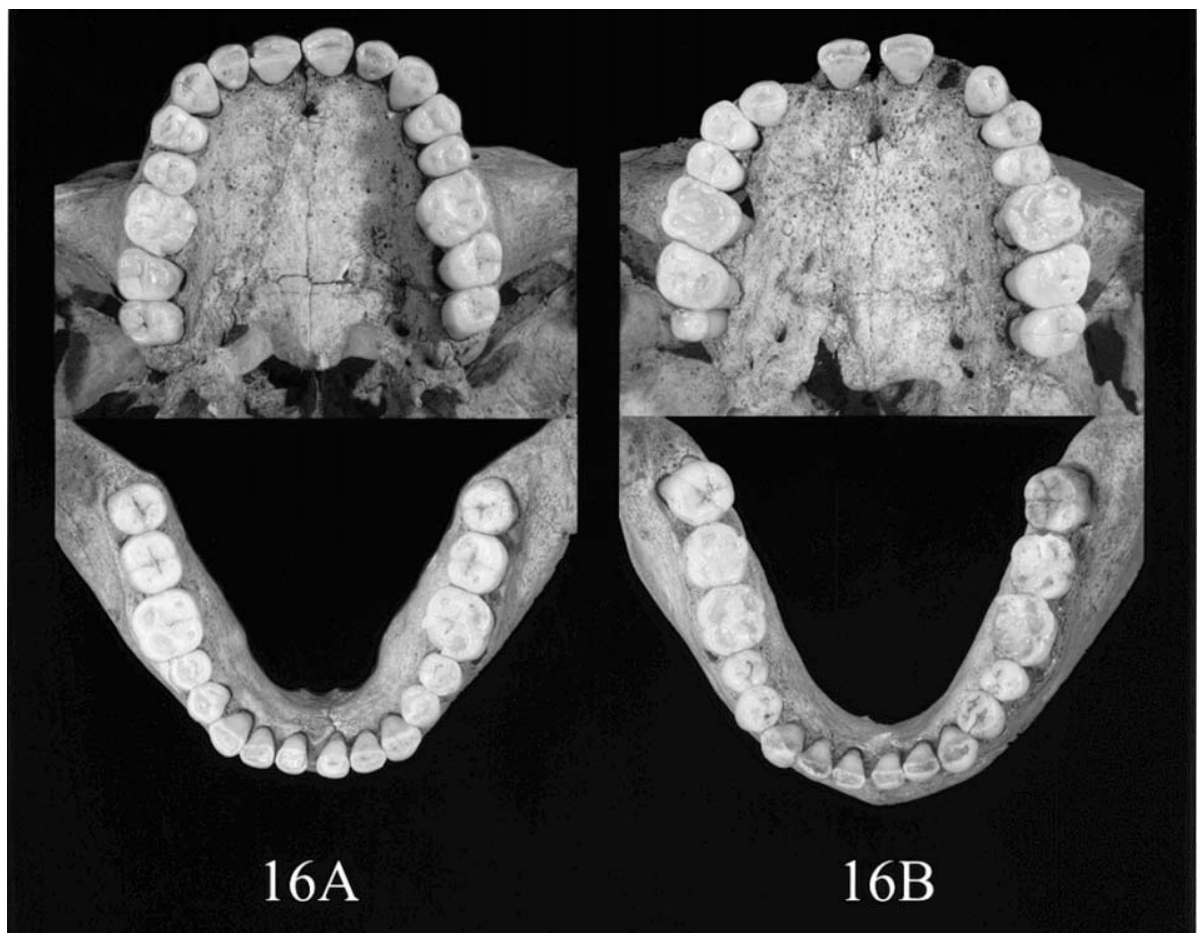

Figure 4. Dentitions of skeletal specimens 16A and 16B. In 16B, the upper right second incisor was intentionally extracted before death and the upper left second incisor was lost after the photograph shown in Figure 3 was taken.

eter of the lower right second incisor and buccolingual diameter of the upper right first molar of specimen 16A and buccolingual diameters of the lower left first incisor, lower left first premolar and lower left first molar of specimen 16B could not be measured due to damage. In these cases, the value of the tooth on the side measured was used as the representative value.

\section{Estimation of the similarity of tooth size proportions}

Based on the tooth crown measurements, Q-mode correlation coefficients (Sokal and Sneath, 1963) were calculated between specimens 16A and 16B. Before calculation, each crown diameter was standardized by using the means and standard deviations of female Jomon data reported by Matsumura (1995). The combinations of tooth crown diameters used for calculation of the Q-mode correlation coefficients 
Table 2. Mesiodistal and buccolingual crown diameters of specimen 16A and 16B, and statistics of the pooled female Jomon sample

\begin{tabular}{|c|c|c|c|c|c|}
\hline & \multirow{2}{*}{$\begin{array}{c}16 \mathrm{~A} \\
\text { Mean }(\mathrm{mm})\end{array}$} & \multirow{2}{*}{$\frac{16 \mathrm{~B}}{\mathrm{Mean}(\mathrm{mm})}$} & \multicolumn{3}{|c|}{ Jomon $^{1}$} \\
\hline & & & $n$ & Mean (mm) & $\mathrm{SD}$ \\
\hline \multicolumn{6}{|l|}{ Mesiodistal diameters } \\
\hline Upper first incisor (UI1) & 7.72 & 7.75 & 74 & 8.28 & 0.42 \\
\hline Upper second incisor (UI2) & 6.23 & $* * *$ & 78 & 6.84 & 0.51 \\
\hline Upper canine (UC) & 7.22 & 7.29 & 54 & 7.33 & 0.52 \\
\hline Upper first premolar (UP1) & 6.45 & 6.64 & 127 & 6.65 & 0.48 \\
\hline Upper second premolar (UP2) & 5.68 & 5.95 & 164 & 6.30 & 0.44 \\
\hline Upper first molar (UM1) & 9.78 & 9.65 & 174 & 9.90 & 0.49 \\
\hline Upper second molar (UM2) & 7.85 & 8.87 & 150 & 8.81 & 0.54 \\
\hline Lower first incisor (LI1) & 4.75 & 5.10 & 49 & 5.23 & 0.41 \\
\hline Lower second incisor (LI2) & 5.29 & 5.66 & 62 & 5.70 & 0.36 \\
\hline Lower canine $(\mathrm{LC})$ & 5.99 & 6.65 & 85 & 6.50 & 0.37 \\
\hline Lower first premolar (LP1) & 5.98 & 6.94 & 165 & 6.61 & 0.47 \\
\hline Lower second premolar (LP2) & 5.57 & 6.54 & 187 & 6.68 & 0.52 \\
\hline Lower first molar (LM1) & 10.26 & 11.40 & 209 & 11.15 & 0.49 \\
\hline Lower second molar (LM2) & 8.97 & 10.55 & 200 & 10.44 & 0.58 \\
\hline \multicolumn{6}{|l|}{ Buccolingual diameters } \\
\hline UI1 & 6.81 & 6.58 & 93 & 7.00 & 0.34 \\
\hline UI2 & 6.17 & $* * *$ & 95 & 6.38 & 0.38 \\
\hline UC & 7.63 & 6.75 & 58 & 7.71 & 0.51 \\
\hline UP1 & 8.65 & 8.69 & 124 & 8.96 & 0.55 \\
\hline UP2 & 8.17 & 8.61 & 165 & 8.75 & 0.52 \\
\hline UM1 & 11.11 & 11.50 & 176 & 11.37 & 0.48 \\
\hline UM2 & 9.96 & 11.13 & 151 & 10.97 & 0.58 \\
\hline LI1 & 5.60 & 5.51 & 59 & 5.68 & 0.34 \\
\hline LI2 & 5.86 & 5.90 & 78 & 6.10 & 0.43 \\
\hline LC & 6.68 & 6.96 & 88 & 7.11 & 0.40 \\
\hline LP1 & 6.85 & 7.99 & 167 & 7.50 & 0.51 \\
\hline LP2 & 6.96 & 7.56 & 190 & 8.02 & 0.52 \\
\hline LM1 & 10.47 & 11.02 & 210 & 10.83 & 0.48 \\
\hline LM2 & 8.60 & 10.25 & 197 & 10.06 & 0.51 \\
\hline
\end{tabular}

*** Upper second incisors of specimen $16 \mathrm{~B}$ could not be measured. Right side was extracted before death, and left side was lost after the photograph shown in Figure 3 was taken.

${ }^{1}$ From Matsumura (1995).

are given in Table 3 . These combinations were selected in such a way that the risk of accidental resemblance was less than $20 \%$ according to the criteria of Doi et al. (1986).

\section{Sequence analysis of mitochondrial DNA}

Intensive precautionary measures against modern DNA contamination were taken as described elsewhere (Adachi et al., 2003). DNA was extracted from the upper left third molar of specimen 16A and a piece of the left femur of specimen 16B according to the method of Adachi et al. (2004).

A segment of HVR 1 [np 16209 to 16402 (16209-16402), relative to the revised Cambridge reference sequence (Andrews et al., 1999)], which is known to be highly polymorphic and proved to be effective for ancient DNA analysis (e.g. Horai et al., 1989; Shinoda and Kanai, 1999), was amplified and sequenced as described elsewhere (Adachi et al., 2004).

\section{Results and Discussion}

In all combinations of the tooth crown diameters examined, the Q-mode correlations were consistently low (Table 3). Doi et al. (1986) regarded a Q-mode correlation coefficient of 0.5 as the criterion of kinship. However, in the present study, the value of the Q-mode correlation coefficient was negative in 13 out of 20 combinations of tooth crown diameters. The highest value of Q-mode correlation coefficient $(0.451)$ was obtained by using six variables, and there was a tendency for an increase in the number of variables to lead to a decrease in the value of the Q-mode correlation coefficient (Table 3 ).

Even if the value of the Q-mode correlation coefficient is high, there is a considerable risk of stochastic resemblance when the number of variables is small. Generally, the risk of stochastic resemblance can be reduced by increasing the number of variables. This means that the increase in the number of variables raises the precision of similarity analysis. In consequence, the tendency observed in the present study indicates that the teeth of the two skeletons examined were morphologically dissimilar. Therefore, from a morphological viewpoint, the possibility that specimens $16 \mathrm{~A}$ and $16 \mathrm{~B}$ were relatives is low.

The mtDNA sequences of specimens $16 \mathrm{~A}$ and $16 \mathrm{~B}$ could be determined unambiguously. Compared to the revised Cambridge reference sequence, a C-to- $\mathrm{T}$ substitution at position 16223, a T-to-C substitution at position 16325 and a T-to-C substitution at position 16362 were observed in specimen 16A, and a C-to-T substitution at position 16223 and an A-to-G substitution at position 16247 were observed in specimen 16B. Basically, among maternal relatives, the mtDNA sequence is identical. On the other hand, as shown above, the mtDNA sequences of the two skeletons were apparently different. Therefore, maternal kinship of the specimens $16 \mathrm{~A}$ and $16 \mathrm{~B}$ is denied with a high level of certainty.

Lack of paternal kinship can be confirmed indisputably if 
Table 3. Combinations of tooth crown diameters and Q-mode correlation coefficients

\begin{tabular}{|c|c|c|}
\hline Combination of crown diameters ${ }^{\mathrm{a}}$ & Number of variables & Q-mode correlation coefficients \\
\hline $\begin{array}{l}\text { (1) } \mathrm{MD}\left(\mathrm{I}^{1} \cdot \mathrm{UC} \cdot \mathrm{P}^{1} \cdot \mathrm{P}^{2} \cdot \mathrm{M}^{1} \cdot \mathrm{M}^{2} \cdot \mathrm{I}_{1} \cdot \mathrm{I}_{2} \cdot \mathrm{LC} \cdot \mathrm{P}_{1} \cdot \mathrm{P}_{2} \cdot \mathrm{M}_{1} \bullet \mathrm{M}_{2}\right) \\
\cdot \mathrm{BL}\left(\mathrm{I}^{1} \cdot \mathrm{UC} \cdot \mathrm{P}^{1} \cdot \mathrm{P}^{2} \cdot \mathrm{M}^{1} \cdot \mathrm{M}^{2} \cdot \mathrm{I}_{1} \cdot \mathrm{I}_{2} \cdot \mathrm{LC} \cdot \mathrm{P}_{1} \cdot \mathrm{P}_{2} \cdot \mathrm{M}_{1} \bullet \mathrm{M}_{2}\right)\end{array}$ & 26 & -0.334 \\
\hline $\begin{array}{l}\text { (2) } \mathrm{MD}\left(\mathrm{I}^{1} \cdot \mathrm{UC} \cdot \mathrm{P}^{1} \cdot \mathrm{P}^{2} \cdot \mathrm{M}^{1} \cdot \mathrm{I}_{1} \cdot \mathrm{I}_{2} \cdot \mathrm{LC} \cdot \mathrm{P}_{1} \cdot \mathrm{P}_{2} \cdot \mathrm{M}_{1}\right) \\
\cdot \operatorname{BL~}\left(\mathrm{I}^{1} \cdot \mathrm{UC} \cdot \mathrm{P}^{1} \cdot \mathrm{P}^{2} \cdot \mathrm{M}^{1} \cdot \mathrm{I}_{1} \cdot \mathrm{I}_{2} \cdot \mathrm{LC} \cdot \mathrm{P}_{1} \cdot \mathrm{P}_{2} \cdot \mathrm{M}_{1}\right)\end{array}$ & 22 & -0.204 \\
\hline $\begin{array}{l}\text { (3) } \mathrm{MD}\left(\mathrm{I}^{1} \cdot \mathrm{UC} \cdot \mathrm{M}^{1} \cdot \mathrm{M}^{2} \cdot \mathrm{I}_{1} \cdot \mathrm{I}_{2} \cdot \mathrm{LC} \cdot \mathrm{M}_{1} \cdot \mathrm{M}_{2}\right) \\
\cdot \operatorname{BL~}\left(\mathrm{I}^{1} \cdot \mathrm{UC} \cdot \mathrm{M}^{1} \cdot \mathrm{M}^{2} \cdot \mathrm{I}_{1} \cdot \mathrm{I}_{2} \cdot \mathrm{LC} \cdot \mathrm{M}_{1} \cdot \mathrm{M}_{2}\right)\end{array}$ & 18 & -0.494 \\
\hline 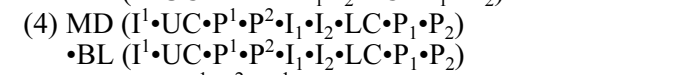 & 18 & -0.198 \\
\hline $\begin{array}{l}\text { (5) } \mathrm{MD}\left(\mathrm{UC} \cdot \mathrm{P}^{1} \cdot \mathrm{P}^{2} \cdot \mathrm{M}^{1} \cdot \mathrm{LC} \cdot \mathrm{P}_{1} \cdot \mathrm{P}_{2} \cdot \mathrm{M}_{1}\right) \\
\cdot \mathrm{BL}\left(\mathrm{UC} \cdot \mathrm{P}^{1} \cdot \mathrm{P}^{2} \cdot \mathrm{M}^{1} \cdot \mathrm{LC} \cdot \mathrm{P}_{1} \cdot \mathrm{P}_{2} \cdot \mathrm{M}_{1}\right)\end{array}$ & 16 & -0.229 \\
\hline (6) $\begin{aligned} \mathrm{MD}\left(\mathrm{P}^{1} \cdot \mathrm{P}^{2} \cdot \mathrm{M}^{1} \cdot \mathrm{M}^{2} \cdot \mathrm{P}_{1} \cdot \mathrm{P}_{2} \cdot \mathrm{M}_{1} \cdot \mathrm{M}_{2}\right) \\
\cdot \mathrm{BL}\left(\mathrm{P}^{1} \cdot \mathrm{P}^{2} \cdot \mathrm{M}^{1} \cdot \mathrm{M}^{2} \cdot \mathrm{P}_{1} \cdot \mathrm{P}_{2} \cdot \mathrm{M}_{1} \cdot \mathrm{M}_{2}\right)\end{aligned}$ & 16 & -0.126 \\
\hline $\begin{array}{l}\text { (7) } \mathrm{MD}\left(\mathrm{I}_{1} \bullet \mathrm{I}_{2} \bullet \mathrm{LC} \cdot \mathrm{P}_{1} \bullet \mathrm{P}_{2} \bullet \mathrm{M}_{1} \bullet \mathrm{M}_{2}\right) \\
\cdot \operatorname{BL}\left(\mathrm{I}_{1} \bullet \mathrm{I}_{2} \cdot \mathrm{LC} \cdot \mathrm{P}_{1} \bullet \mathrm{P}_{2} \bullet \mathrm{M}_{1} \bullet \mathrm{M}_{2}\right)\end{array}$ & 14 & -0.183 \\
\hline (8) $\mathrm{MD}\left(\mathrm{P}^{1} \cdot \mathrm{P}^{2} \bullet \mathrm{M}^{1} \cdot \mathrm{P}_{1} \cdot \mathrm{P}_{2} \cdot \mathrm{M}_{1}\right) \cdot \mathrm{BL}\left(\mathrm{P}^{1} \cdot \mathrm{P}^{2} \cdot \mathrm{M}^{1} \cdot \mathrm{P}_{1} \cdot \mathrm{P}_{2} \cdot \mathrm{M}_{1}\right)$ & 12 & 0.051 \\
\hline (9) $\mathrm{MD}\left(\mathrm{I}^{1} \cdot \mathrm{UC} \cdot \mathrm{P}^{1} \cdot \mathrm{P}^{2} \cdot \mathrm{M}^{1} \cdot \mathrm{M}^{2}\right) \cdot \mathrm{BL}\left(\mathrm{I}^{1} \cdot \mathrm{UC} \cdot \mathrm{P}^{1} \cdot \mathrm{P}^{2} \cdot \mathrm{M}^{1} \cdot \mathrm{M}^{2}\right)$ & 12 & -0.227 \\
\hline$(10) \mathrm{MD}\left(\mathrm{I}^{1} \cdot \mathrm{UC} \cdot \mathrm{P}^{1} \cdot \mathrm{P}^{2} \cdot \mathrm{M}^{1}\right) \cdot \mathrm{BL}\left(\mathrm{I}^{1} \cdot \mathrm{UC} \cdot \mathrm{P}^{1} \cdot \mathrm{P}^{2} \cdot \mathrm{M}^{1}\right)$ & 10 & 0.135 \\
\hline (11) $\mathrm{MD}\left(\mathrm{UC} \cdot \mathrm{P}^{1} \cdot \mathrm{P}^{2} \cdot \mathrm{M}^{1}\right) \cdot \mathrm{BL}\left(\mathrm{UC} \cdot \mathrm{P}^{1} \cdot \mathrm{P}^{2} \cdot \mathrm{M}^{1}\right)$ & 8 & -0.097 \\
\hline (12) $\mathrm{MD}\left(\mathrm{P}^{1} \cdot \mathrm{M}^{1} \cdot \mathrm{P}_{1} \cdot \mathrm{M}_{1}\right) \cdot \mathrm{BL}\left(\mathrm{P}^{1} \cdot \mathrm{M}^{1} \cdot \mathrm{P}_{1} \cdot \mathrm{M}_{1}\right)$ & 8 & -0.757 \\
\hline (13) $\mathrm{MD}\left(\mathrm{P}_{1} \cdot \mathrm{P}_{2} \cdot \mathrm{M}_{1} \bullet \mathrm{M}_{2}\right) \cdot \mathrm{BL}\left(\mathrm{P}_{1} \cdot \mathrm{P}_{2} \bullet \mathrm{M}_{1} \bullet \mathrm{M}_{2}\right)$ & 8 & 0.382 \\
\hline (14) $\mathrm{MD}\left(\mathrm{P}^{1} \cdot \mathrm{P}^{2} \cdot \mathrm{M}^{1}\right) \cdot \mathrm{BL}\left(\mathrm{P}^{1} \cdot \mathrm{P}^{2} \cdot \mathrm{M}^{1}\right)$ & 6 & 0.451 \\
\hline (15) $\mathrm{MD}\left(\mathrm{I}^{1} \cdot \mathrm{UC} \cdot \mathrm{P}^{1} \cdot \mathrm{P}^{2} \cdot \mathrm{M}^{1} \cdot \mathrm{M}^{2} \cdot \mathrm{I}_{1} \cdot \mathrm{I}_{2} \cdot \mathrm{LC} \cdot \mathrm{P}_{1} \cdot \mathrm{P}_{2} \cdot \mathrm{M}_{1} \cdot \mathrm{M}_{2}\right)$ & 13 & -0.150 \\
\hline (16) $\mathrm{MD}\left(\mathrm{I}^{1} \cdot \mathrm{UC} \cdot \mathrm{P}^{1} \cdot \mathrm{P}^{2} \cdot \mathrm{M}^{1} \cdot \mathrm{I}_{1} \cdot \mathrm{I}_{2} \cdot \mathrm{LC} \cdot \mathrm{P}_{1} \cdot \mathrm{P}_{2} \cdot \mathrm{M}_{1}\right)$ & 11 & -0.038 \\
\hline (17) $\mathrm{MD}\left(\mathrm{I}^{1} \cdot \mathrm{UC} \cdot \mathrm{P}^{1} \cdot \mathrm{P}^{2} \cdot \mathrm{I}_{1} \cdot \mathrm{I}_{2} \cdot \mathrm{LC} \cdot \mathrm{P}_{1} \cdot \mathrm{P}_{2}\right)$ & 9 & 0.225 \\
\hline$(18) \mathrm{MD}\left(\mathrm{UC} \cdot \mathrm{P}^{1} \cdot \mathrm{P}^{2} \cdot \mathrm{M}^{1} \cdot \mathrm{LC} \cdot \mathrm{P}_{1} \cdot \mathrm{P}_{2} \cdot \mathrm{M}_{1}\right)$ & 8 & -0.240 \\
\hline (19) $\mathrm{MD}\left(\mathrm{I}^{1} \cdot \mathrm{UC} \cdot \mathrm{P}^{1} \cdot \mathrm{I}_{1} \cdot \mathrm{I}_{2} \cdot \mathrm{LC} \cdot \mathrm{P}_{1}\right)$ & 7 & 0.159 \\
\hline (20) $\mathrm{MD}\left(\mathrm{I}^{1} \cdot \mathrm{UC} \cdot \mathrm{I}_{1} \cdot \mathrm{I}^{2} \cdot \mathrm{LC}\right)$ & 5 & 0.349 \\
\hline
\end{tabular}

${ }^{a} \mathrm{MD}$, mesiodistal diameter; BL, buccolingual diameter.

STR and/or VNTR loci in chromosomal DNA can be analyzed, and these loci have been successfully analyzed in some studies of ancient DNA (e.g. Kurosaki et al. 1993; Hummel et al. 1999). Unfortunately, STR and VNTR analyses were not successful in the present study. Nevertheless, judging from both morphological and genetic evidence, specimens $16 \mathrm{~A}$ and $16 \mathrm{~B}$ are more likely to have been unrelated than consanguineous.

From the archaeological viewpoint, a difference in style of antemortem tooth extraction is estimated to reflect a difference in social and/or personal status, including genealogy (e.g. Harunari, 1982; Yamada, 2003). The fact that antemortem tooth extraction was observed only in specimen $16 \mathrm{~B}$ is considered to strengthen this hypothesis. Moreover, the opposing head directions of specimens $16 \mathrm{~A}$ and $16 \mathrm{~B}$ might reflect the lack of kinship between them.

On the other hand, both skeletons wore shell bracelets on their left forearms, and both were buried in the fetal position. These common findings may indicate some relationship other than kinship between specimens $16 \mathrm{~A}$ and $16 \mathrm{~B}$ that resulted in these individuals being buried together.

The results of the present study suggest that the Jomon people, at least in Hokkaido, had the custom of burying genealogically different people side by side at the same time in the Final Jomon era. To clarify how genealogical differences are related to difference in burial style, or to examine if this type of double burial exists outside Hokkaido, skeletons discovered from other double burials should be analyzed morphologically, genetically and archaeologically.

\section{Acknowledgments}

The authors would like to thank Dr Yasuhiro Yamada of Shimane University, Japan for advice and help in writing this paper. A Grant-in-Aid for Young Scientists (No. 15770157) from the Japanese Ministry of Education, Science, Sports and Culture sponsored this study.

\section{References}

Adachi N., Dodo Y., Ohshima N., Doi N., Yoneda M., and Matsumura H. (2003) Morphologic and genetic evidence for the kinship of juvenile skeletal specimens from a 2,000 yearold double burial of the Usu-Moshiri site, Hokkaido, Japan. Anthropological Science, 111: 347-363.

Adachi N., Umetsu K., Takigawa W., and Sakaue K. (2004) Phylogenetic analysis of the human ancient mitochondrial DNA. Journal of Archaeological Science, 31: 1339-1348.

Alt K.W., Pichler S., Vach W., Klíma B., Vlcek E., and Sedlmeier J. (1997) Twenty-five thousand-year-old triple burial from Dolní Vêstonice: an Ice-Age family? American Journal of Physical Anthropology, 102: 123-131.

Andrews R.M., Kubacka I., Chinnery P.F., Lightowlers R.N., Turnbull D.M., and Howell N. (1999) Reanalysis and revision of the Cambridge reference sequence for human mitochondrial DNA. Nature Genetics, 23: 147.

Corruccini R.S., Shimada I., and Shinoda K. (2002) Dental and mtDNA relatedness among thousand-year-old remains from Huaca Loro, Peru. Dental Anthropology, 16: 9-14.

Delefosse T. and Hänni C. (1997) Molecular archaeology: familial relationship into a Neolithic deposit. Comptes Rendus des Séances de la Société de Biologie et de ses Filiales, 191: 521528. 
Doi N., Tanaka Y., and Funakoshi K. (1985) An approach on kinship among skeletal remains from Uenoharu tunnel-tombs, Oita Prefecture. Journal of the Anthropological Society of Nippon, 93: 206 (in Japanese).

Doi N., Tanaka Y., and Funakoshi K. (1986) A method for estimation of kinship based on the tooth measurements and its application to the ancient human skeletons. Journal of the Anthropological Society of Nippon, 94: 147-162 (in Japanese).

Fujita T. (1949) On the standard for measurement of teeth. The Journal of the Anthropological Society of Nippon, 61: 27-32 (in Japanese).

Hanihara K., Yamauchi A., and Mizoguchi Y. (1983) Statistical analysis on kinship among skeletal remains excavated from a Neolithic site at Uwasato, Iwate Prefecture. Journal of the Anthropological Society of Nippon, 91: 49-68 (in Japanese).

Harunari H. (1982) An argument on the Jomon society. In: Fujimoto T., Kato S., and Kobayashi T. (eds.), A Study on the Jomon Culture, Volume 8: Society and Culture. Yuzankaku Shuppan, Tokyo, pp. 223-252 (in Japanese).

Horai S., Hayasaka K., Murayama K., Wate N., Koike H., and Nakai N. (1989) DNA amplification from ancient human skeletal specimens and their sequence analysis. Proceedings of the Japan Academy, Series B, 65: 229-233.

Hummel S., Schultes T., Bramanti B., and Herrmann B. (1999) Ancient DNA profiling by megaplex amplifications. Electrophoresis, 20: 1717-1721.

Kurosaki K., Matsushita T., and Ueda S. (1993) Individual DNA identification from ancient human remains. American Journal of Human Genetics, 53: 638-643.

Matsumura H. (1995) A microevolutional history of the Japanese people as viewed from dental morphology. National Science Museum Monographs, No. 9, National Science Museum, Tokyo, pp. 1-130.
Matsumura H. and Nishimoto T. (1996) Statistical analysis on kinship of the Nakazuma Jomon people using tooth crown measurements. Zoo-archaeology, 6: 1-17 (in Japanese).

Ohshima N., Ishida H., Dodo Y., and Kawauchi M. (1989) The Usu-10-Site in Hokkaido. Archaeologia Japonica, 40: 347352 (in Japanese).

Ohshima N., Ishida H., Matsumura H., Dodo Y., and Kawauchi M. (1990) The Usu-10-Site, Date, Hokkaido. Archaeologia Japonica, 41: 386-390 (in Japanese).

Oota H., Saitou N., Matsushita T., and Ueda S. (1995) A genetic study of 2000-year-old human remains from Japan using mitochondrial DNA sequences. American Journal of Physical Anthropology, 98: 133-145.

Shinoda K. and Kanai S. (1999) Intracemetry genetic analysis at the Nakazuma Jomon site in Japan by mitochondrial DNA sequencing. Anthropological Science, 107: 129-140.

Shinoda K., Matsumura H., and Nishimoto T. (1998) Genetical and morphological analysis on kinship of the Nakazuma Jomon people using mitochondrial DNA and tooth crown measurement. Zoo-archaeology, 11: 1-21 (in Japanese).

Sjøvold T. (1975) Allocation of single or some few individuals to one of two or more groups by means of non-metrical variants in the skeleton. Osaa, 2: 41-46.

Sokal R.R. and Sneath P.H.A. (1963) Principles of Numerical Taxonomy. W.H. Freeman and Company, San Francisco.

Spence M.W. (1974) Residential practices and the distribution of skeletal traits in Teotihuácan, Mexico. Man, 9: 262-273.

Tanaka Y. (1995) A Study on Kin-Structure of Kofun Period in Japan. Kashiwa Shobo, Tokyo (in Japanese).

Yamada Y. (2003) Does head direction reflect the social structure?-re-examination by using the skeletons unearthed from the Jomon archaeological site- - In: Ritsumeikan University (eds.), Collected Papers on Archaeology 3. Ritsumeikan University, Kyoto, pp. 341-366 (in Japanese). 